\title{
Research and Application of Influences of Lateral Pressure Coefficients on the Extension Angle of Coal Cracks
}

\author{
Cheng Liu, ${ }^{1,2,3}$ Shu-gang Li, ${ }^{1,2}$ Song Qin, ${ }^{3}$ and Shou-guo Yang ${ }^{1,2}$ \\ ${ }^{1}$ College of Safety Science and Engineering, Xian University of Science and Technology, Xi'an 710054, China \\ ${ }^{2}$ Key Laboratory of Western Mine Exploitation and Hazard Prevention of Ministry of Education, \\ Xian University of Science and Technology, Xian 710054, China \\ ${ }^{3}$ Chongqing Research Institute of China Coal Technology Engineering Group, Chongqing 400039, China
}

Correspondence should be addressed to Cheng Liu; kyzj31@126.com

Received 22 May 2016; Revised 27 July 2016; Accepted 1 August 2016

Academic Editor: Yuanxin Zhou

Copyright (C) 2016 Cheng Liu et al. This is an open access article distributed under the Creative Commons Attribution License, which permits unrestricted use, distribution, and reproduction in any medium, provided the original work is properly cited.

Fluid-solid coupling seepage fields are ubiquitous in engineering practices. However, few investigations have been carried out on the rules of crack extension of solids under the effect of fluids. By using the RFPA2D (realistic failure process analysis in 2 dimensions), this research studied the influences of different lateral pressure coefficients on the extension direction and length of coal cracks. Also the result can be proved by fracture mechanics, stress intensity factor theory, and sliding crack theory. On this basis, aiming at a coal mine with the mining depth being over $700 \mathrm{~m}$, the reliability of the above conclusion was further proved by testing the crustal stress at the positions with the buried depth varying from $750 \mathrm{~m}$ to $1,300 \mathrm{~m}$. At the same time, in condition of meeting the water pressure required by the crack extension, permeability-increasing radius is selected preferably through $\mathrm{AE}$ energy index by simulation of hydraulic fracturing for coal seams under different lateral pressure coefficients, and the gas drainage achieves good effect in engineering practice.

\section{Introduction}

At present, engineering technologies have been popularized in various fields, such as the disposal of nuclear wastes, in situ stress measurement in petroleum exploration engineering, geothermal monitoring, environmental engineering, micromechanics, and military. Under such context, studies on cracks rapidly develop. According to the statistics, seepage technology has been indispensable in energy exploitation, environmental protection, medical technology, and largescale water conservancy and hydropower projects. The combination of seepage mechanics and rock and soil mechanics has been extensively applied in studies including coal bed methane (CBM) seepage, fluid-solid coupling in exploitation process of petroleum, and transportation. At present, there have been many studies on the crack extension. For instance, Shan et al. [1] found that cracks in fractured coal seams generally extend through the upper and lower interlayer of the coal seams in the production process of CBM, even exceeding four times the thickness of the fractured coal seams at maximum. The cracks are generally $50-70 \mathrm{~m}$ in length and mainly demonstrated as vertical cracks, along with the coexistence of vertical cracks and horizontal cracks. In addition, few vertical cracks are found in one side of fractured wells. Though cracks extend randomly, they are more likely to extend in one direction, indicating that crack extension is caused by the joint effect of crustal stress, local stratigraphic structure, and cleats in coal seams. To solve the low extraction efficiency of CBM caused by the random extension of hydraulic fractures in underground coal seams, Xia et al. [2] arranged pilot holes around fractured holes. Both the fractured holes and the pilot holes then extend to form oriented cracks by using water jet slotting technology. Under the effect of crustal stress, shear failure zones are formed at the tips of cracks, while cracks initiate from the tips under the effect of internal water pressure. By calculating the maximal principal stress of cracks generated by water jet slotting technology along the horizontal extension direction, 
it is obtained that cracks extend along the horizontal direction after initiating from the tips. Baiquan et al. [3] based their work on the method of combination of theoretical analysis and field tests. The permeability-increasing mechanism of network slotting boreholes was studied, and the permeabilityincreasing technology of network slotted boreholes crossing from floor was proposed. Shugang et al. [4] found the suitable hydraulic fracturing technology parameters for coal seams through the analysis of permeability-increasing mechanism. Chenye et al. [5] investigated the influence of initial fissure and ground stress on the crack initiation and expanding of hydraulic fracturing, obtaining the variation trend of initiation pressure and direction with the lateral pressure coefficient and initiation pressure and direction of the models without preset crack and with preset crack are comparatively analyzed. At the end, the effect theory of in situ stress and original defect to the hydraulic fracturing initiation is elaborated by stress analysis. Wei et al. [6] conclude that the floor area could be divided into initial stress region, pressure relieved and permeability enhanced region, and recompacted region. Also, the coal permeability enhancement was accompanied with its swelling; the mining-induced floor fracture became fracture gas channel connecting the protected coal seam to the protective working face. Zhang et al. [7] used linear elastic theory to present formulas of maximal tangential stress and critical load. Also, opening point, opening angle, maximal tangential stress, and critical load vary with aspect ratio and inclined angle.

This research paid attention to the influence of the joint effect of horizontal principal stress and vertical principle stress on crack extension. That is, the authors explored the influence rule of different lateral pressure coefficients on the extension direction of cracks in fluid-solid coupling by using theoretical analysis and numerical simulation, and the result of crustal stress measurement proves that the relationship between lateral pressure coefficients and extension direction of cracks is true. At the same time, the superior gas drainage radius is chosen by $\mathrm{AE}$ energy index through simulation of hydraulic fracturing under different value of lateral pressure coefficients, and effect of gas drainage is great so as to provide guidance for engineering practices.

\section{Theoretical Analysis for Fracture Extension}

In seepage fields, the extension of cracks depends on the initiation pressure. The influencing factors include lithology and stress distributions around cracks and the angle between cracks and the maximal unbalanced force. The method of elastic mechanics [8] for calculating initiation pressure is applied in two steps: firstly, it needs to calculate the stress distribution around boreholes; in the second step, cracks gradually extend once the rock failure conditions in fracture mechanics [9] are satisfied, that is, when the stress field around cracks is larger than the strength of rocks. In recent years, with the development of fracture mechanics and damage mechanics [10], many scholars have theoretically analyzed the fracture initiation from the perspective of fracture damage [11]. (1) According to the maximal principal

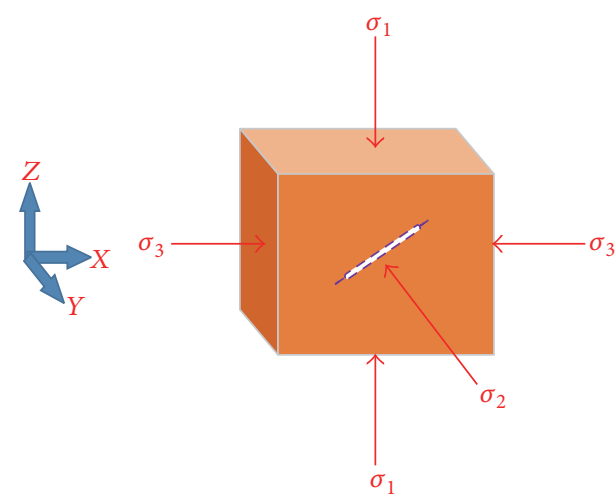

FIGURE 1: The structural model of a unit cell subjected to stresses from three directions.

stress theory, when a material is under the effect of complex stress, yield failure occurs when the maximal principal stress subjected by the specimen is at least equal to the normal yield stress of this specimen in a simple tensile test. (2) Based on the maximal principal strain theory, when the maximal principal strain of a specimen equals the strain corresponding to the yield stress in a simple tensile test, yield failure happens to this specimen. (3) With regard to the maximal shear stress theory, the maximal shear stress imposed on materials is larger than the half of the normal stress they bear. (4) On the basis of total strain energy, when the total strain energy equals that of materials being simply stretched, the materials yield and therefore are fractured. (5) Considering strain energy of distortion, when the distortion energy reaches tensile yield, yield failure occurs to materials. (6) Mohr's stress circle theory developed from the maximal shear stress theory which is applicable to both the extension and the compression of materials can also be employed.

In this study, Mohr's stress circle theory was mainly used to analyze the extension of cracks. The extension of slits is mainly determined by many factors, such as the lithology of rocks, stress around the slits, the angle between the slits and the maximal principal stress along the horizontal direction, and the shape of slits. To investigate the extension rules of slits, it is firstly needed to determine the conditions under which slits extend, that is, the extension criteria of slits. Meanwhile, orthogonal experiment generally needs to be designed through numerical simulation to find the rules. To study the extension rules of cracks, it is supposed to start with the force analysis of cracks which are mainly influenced by the horizontal principal stress and vertical principal stress. As the rules cannot be found by merely considering the horizontal principal stress or vertical principal stress, we can investigate the extension of cracks in terms of lateral pressure coefficients.

By taking the model of the unit cell containing the crack out, it can be found that it is subjected to the stresses from three directions [12], as shown in Figure 1. Thereinto, $\sigma_{1}$ and $\sigma_{2}$ show the horizontal principal stresses. When $\sigma_{1}>\sigma_{2}$, $\sigma_{1}$ represents the maximal vertical principal stress, while $\sigma_{3}$ denotes the principal stress in the horizontal direction. 


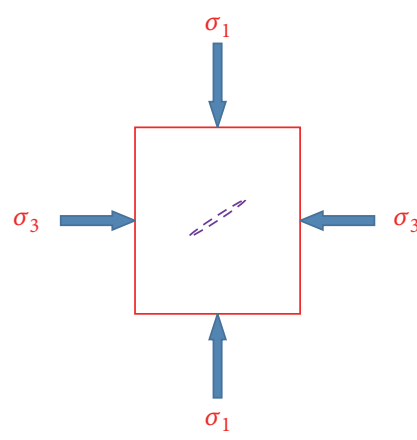

(a) Closure of initial fractures

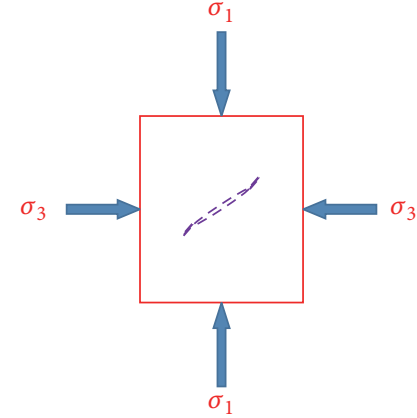

(b) Initiation of wing cracks

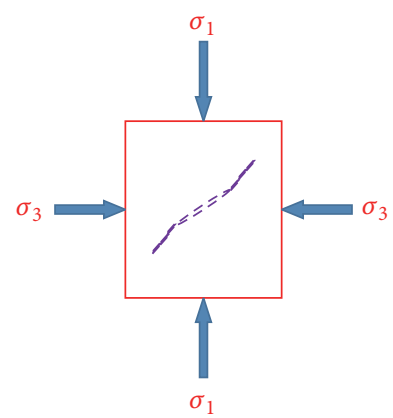

(c) Extension of wing cracks

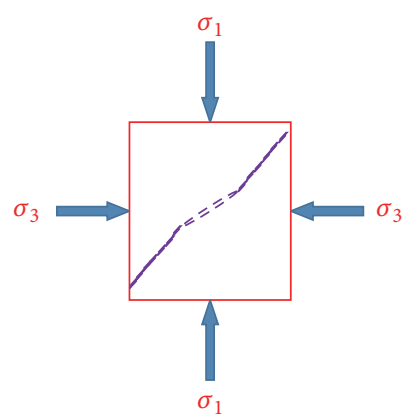

(d) Destruction of units

FIGURE 2: Evolution law of fracture-induced failure.

Generally, these three factors are not equal. Therefore, the lateral pressure coefficient under such condition is [13-16]

$$
\lambda=\frac{\sigma_{2}+\sigma_{3}}{2 \sigma_{1}} .
$$

However, it is generally considered that the two horizontal stresses are equal; that is, $\sigma_{2}=\sigma_{3}$ in 2-dimensional models. Under such circumstance, $2 \mathrm{D}$ numerical simulation can be carried out by just measuring the confining pressure and the pressure in the vertical direction. The lateral pressure coefficient is simplified as follows:

$$
\lambda^{\prime}=\frac{\sigma_{3}}{\sigma_{1}} .
$$

Cracks are symmetric in the space. On the premise of assuming that $\sigma_{2}=\sigma_{3}$, it is just needed to study the mechanical distribution law of $X-Z$ planes at slits. Aiming at the technological process based on hydrofracturing, preslotting is performed to the regions where the permeability needs to be increased through relieving pressure, followed by the injection of water at a high pressure into these slits. Under the coupling effect of stress and seepage, cracks in fractured rock masses develop in a manner conforming to the evolution process of rocks from initial fractures to wing rupture, as shown in Figure 2.

Open cracks under the effect of fluid-solid coupled fields are demonstrated in Figure 3. In this figure, (a) and (b) are the half lengths of the major semiaxis and minor semiaxis of the oval slotted crack, respectively, while $\theta$ shows the angle between the initiation and extension direction of wing cracks and the dip angle of initial cracks. According to the elastic mechanics theory, the stresses $\sigma_{N}$ and $\sigma_{T}$ on the main crack surface are expressed by using far field compressive stresses $\sigma_{1}$ and $\sigma_{3}$ as follows:

$$
\begin{aligned}
\sigma_{T} & =\frac{1}{2}\left[\left(\sigma_{1}+\sigma_{3}\right)-\left(\sigma_{1}-\sigma_{3}\right) \cos (2 \beta)\right]-P \\
& =\sigma_{1}\left(\sin ^{2} \beta+\lambda \cos ^{2} \beta\right)-P \\
\sigma_{N} & =\frac{1}{2}\left[\left(\sigma_{1}+\sigma_{3}\right)+\left(\sigma_{1}-\sigma_{3}\right) \cos (2 \beta)\right]-P \\
& =\sigma_{1}\left(\cos ^{2} \beta+\lambda \sin ^{2} \beta\right)-P
\end{aligned}
$$

$$
\tau=\frac{1}{2}\left(\sigma_{1}-\sigma_{3}\right) \sin 2 \beta=\frac{1}{2} \sigma_{1}(1-\lambda) \sin 2 \beta,
$$

where $\beta$ is the angle between the crack surface and the $X$ direction; $P$ shows the seepage water pressure acted on the crack surface; and $\tau$ represents the shear stress on the main crack surface, while $\sigma_{N}$ and $\sigma_{T}$ denote the normal pressure stress and horizontal pressure stress on the crack surface, separately.

It is well known that Griffith linear cracks conform to the classical sliding crack model. When the slit is a notch with a certain thickness $(b \neq 0)$ and the radius of curvature at the crack tip does not always equal $0, \sigma_{T} \neq 0$ and I stress intensity factor is supposed to be generated under the effect of this tensile stress. This factor is superposed with the normal pressure stress, thus forming the following stress intensity factor:

$$
\begin{aligned}
K_{\mathrm{I}} & =\sqrt{\pi a}\left(\frac{1}{2} \sigma_{T} \sqrt{\frac{\rho}{a}}-\sigma_{N}\right)=\frac{1}{2} \\
\cdot & \sqrt{\pi a}\left\{\frac{1}{2}\left[(1+\lambda) \sigma_{1}+(1-\lambda) \sigma_{1} \cos 2 \beta\right] \sqrt{\frac{\rho}{a}}\right. \\
& \left.-\left[(1+\lambda) \sigma_{1}+(1-\lambda) \sigma_{1} \cos 2 \beta\right]\right\} .
\end{aligned}
$$

When wing cracks just initiate, they are pure II ruptures with the stress intensity factor presented as follows:

$$
K_{\mathrm{II}}=\tau_{\mathrm{eff}} \sqrt{\pi a}=\frac{1}{2} \sigma_{1}(1-\lambda) \sin 2 \beta \sqrt{\pi a},
$$

where $\tau_{\text {eff }}$ represents the equivalent shear stress on the main crack surface and $\tau_{\text {eff }}=\tau+\mu\left|\sigma_{N}\right|$, where $\mu$ denotes the friction coefficient of the crack surface and valued as 0 for open cracks.

In the light of the release rate theory of strain energy, wing cracks are supposed to initiate and extend along the direction of generating the maximal release rate of strain energy. When the release rate of strain energy along this direction reaches 


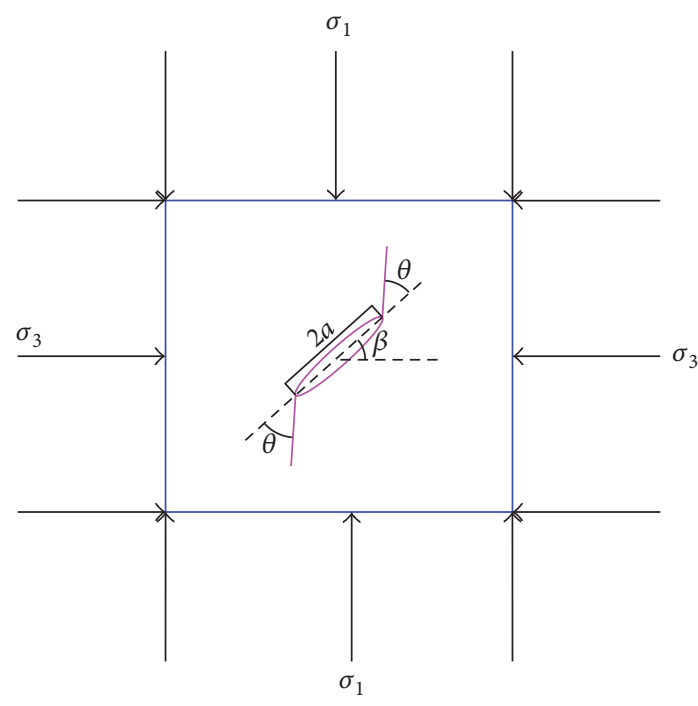

(a) Stress state of slit units

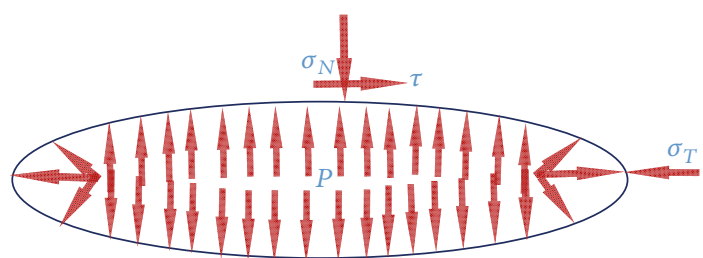

(b) Stress state of slits

Figure 3: Mechanical structural models of fractures.

the critical value, wing cracks initiate or begin to extend and are expressed by

$$
\begin{gathered}
G(\theta)=\frac{4}{E}\left(\frac{1+\theta / \pi}{1-\theta / \pi}\right)^{-\theta / \pi}\left[\left(1+3 \cos ^{2} \theta\right) K_{\mathrm{I}}^{2}\right. \\
\left.-4 K_{\mathrm{I}} K_{\mathrm{II}} \sin 2 \theta+\left(9-5 \cos ^{2} \theta\right) K_{\mathrm{II}}^{2}\right] .
\end{gathered}
$$

The initiation angle and loads of wing cracks can be calculated using the following formulas:

$$
\begin{gathered}
\frac{\partial G(\theta)}{\partial \theta}=0 \\
\frac{\partial^{2} G(\theta)}{\partial \theta^{2}}<0 .
\end{gathered}
$$

By combining formulas (8) and (9), it is known that

$$
\begin{aligned}
& {\left[5 K_{\mathrm{II}}^{2} \sin 2 \theta-8 K_{\mathrm{I}} K_{\mathrm{II}} \cos 2 \theta-3 K_{\mathrm{I}}^{2} \sin 2 \theta\right]} \\
& \quad-\left(\frac{1}{\pi} I_{n} \frac{\pi+\theta}{\pi-\theta}+\frac{2 \theta}{\pi^{2}+\theta^{2}}\right)\left[\left(1+3 \cos ^{2} \theta\right) K_{\mathrm{I}}^{2}\right. \\
& \left.\quad-4 K_{\mathrm{I}} K_{\mathrm{II}} \sin 2 \theta+\left(9-5 \cos ^{2} \theta\right) 3 K_{\mathrm{II}}^{2}\right]=0 .
\end{aligned}
$$

\section{Research on the Relationship between Lateral Pressure Coefficients and Extension Angle of Crack (Figure 7)}

3.1. Numerical Simulation for Crack Extension. Under the condition of invariable stress in $Z$ direction, considering the initiation angle of coal cracks to have no bias in $x$ direction or $y$ direction, as illustrated in Figure 3, taking angle of coal cracks as $\beta=45^{\circ}$, with lateral pressure coefficients changing into $\lambda=\sigma_{3} / \sigma_{1}$ according to formula (2), Figure 3 is a model based on numerical simulation of Figure 4 .

Numerical analysis was carried out on the crack process of a rock mass under different lateral pressure coefficients by
TABLE 1: Parameters of the rock mass.

\begin{tabular}{lc}
\hline Mechanical parameters & Values \\
\hline Homogeneity & 3 \\
Elasticity modulus $(\mathrm{GPa})$ & 13 \\
Internal friction angle $\left(^{\circ}\right)$ & 33 \\
Compressive strength $(\mathrm{MPa})$ & 20 \\
Ratio of compressive strength to tensile strength & 17 \\
Coefficient of residual strength & 0.1 \\
Coefficient of pore water pressure & 0.8 \\
Permeability coefficient $(\mathrm{m} / \mathrm{d})$ & 1.0 \\
Poisson's ratio & 0.35 \\
Porosity & 0.15 \\
\hline
\end{tabular}

TABLE 2: Contrastive analysis with different horizontal stresses and vertical stresses.

\begin{tabular}{lllcccccc}
\hline$\sigma_{3} / \mathrm{MPa}$ & 11 & 12 & 12.5 & 13 & 13.5 & 14 & 15 & 16 \\
$\sigma_{1} / \mathrm{MPa}$ & 13 & 13 & 13 & 13 & 13 & 13 & 13 & 13 \\
\hline
\end{tabular}

using software RFPA2D (realistic failure process analysis in 2 dimensions) in seepage-stress coupling. After the parameters were further determined, the extension of the crack was studied by setting different lateral pressure coefficients under the condition that the vertical pressure was maintained as $13 \mathrm{Mpa}$.

Meanwhile, when studying the influencing factors of lateral pressure coefficients, orthogonal experiments [17] can be conducted with $\sigma_{1}$ valued as $13 \mathrm{Mpa}$. Under this condition, we just need to change the values of $\sigma_{3}$. The specific settings are demonstrated in Table 2.

As illustrated in Figure 4, the model shows a size of $200 \mathrm{~m}$ $\times 200 \mathrm{~m}$ with the number of grids being $200 \times 200$. The slit is located in the center of the model and presents an angle of $45^{\circ}$ to the horizontal direction. Then, boundary conditions were set based on Tables 1 and 2 . 


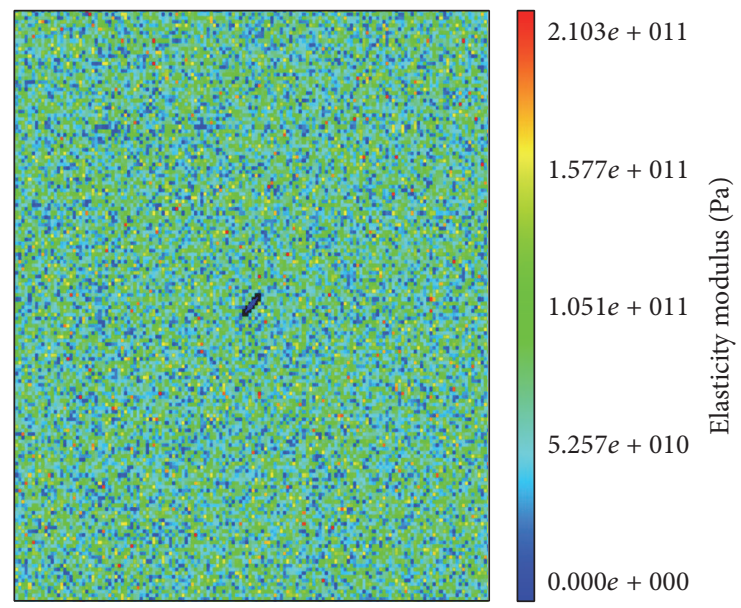

FIgURE 4: The initial model of crack extension.

After water was injected at a pressure of $10 \mathrm{Mpa}$ into the crack, the final extensions of the cracks are demonstrated in Figure 5.

\subsection{Analysis of the Results Obtained in Crack Extension} Simulation. According to Figure 4, the extension rules of cracks are obtained: when the horizontal stress in the $X$ direction is larger than that in the $Z$ direction, cracks extend along the $X$ direction; if the stress in the $X$ direction is at least $1 \mathrm{MPa}$ larger than that in the $Z$ direction, cracks propagate more obviously along the $X$ direction. However, as the horizontal stress in the $X$ direction equals that in the $Z$ direction, cracks extend along the original direction of the cracks, while when the vertical stress in the $Z$ direction is larger than that in the $X$ direction, cracks elongate along the $Z$ direction.

Figure 6 displays the curves concerning the relationship between the lateral pressure coefficient $\lambda=\sigma_{3} / \sigma_{1}$ and the angle $\alpha$ between the crack extension direction and the horizontal direction.

As shown in Figure 6, with the growth of the lateral pressure coefficient, the angle between the crack extension direction and the horizontal direction declines, while when the horizontal stress is infinitely larger than that in the vertical stress, cracks always propagate along the horizontal direction no matter which direction cracks initiate.

3.3. Field Data. Hydrofracturing, as an example of fluid-solid coupling, has been widely used in crustal stress measurement in deep mines. The crustal stress measurement [12] mainly refers to measuring the fundamental factor causing the deformation and failure of surrounding rocks, that is, the stress of primary rocks nearby strata. Understanding the distribution law of crustal stress is of great significance in guiding the overall layout and supporting design of mines, optimal design of stopes, ensuring safety in construction, and improving production productivity. Crustal stress is mainly generated by the joint effect of gravitational field and tectonic field. Thereinto, the horizontal tectonic stress field exerts the largest influence on the crustal stress.

Based on the significance of crustal stress measurement, hydrofracturing is generally applied in coal mines at present as it omits the process of setting mechanical parameters of lithology and operates simply and conveniently. In addition, it is economic and applicable with a little work amount.

In one mine, as the overlying rock strata are hard and thick with complex structures, hydrofracturing was used. Meanwhile, a borescope and a pressure sensor were used to observe the crack extension angle and read relevant stress, separately. Total 18 measuring points were set at different positions with the buried depth varying from $750 \mathrm{~m}$ to $1,300 \mathrm{~m}$ to measure the crustal stress.

According to formula (2), the relationship between the lateral stress coefficient and the angle $\alpha$ between crack extension direction and the horizontal direction is obtained. By drawing this relationship and comparing it with the curve presented in Figure 5, Figure 6 can be acquired.

3.4. Theoretic Verification. The relevant parameters were tested based on ground stress, that is, $a=10 \mathrm{~mm}, \beta=45^{\circ}$, $\rho / a=0.05$, and $\sigma_{1}=13 \mathrm{MPa}$. The comparison between the coupling curves solved using (6), (7), and (10) and the curves for crack propagation tested using ground stress in Section 3.3 are illustrated in Figure 8. The results obtained in the presence of an allowable error further verified the correctness of simulated outcome in Section 3.1.

\section{Application in Gas Drainage Project Based on the Relationship between Lateral Pressure Coefficient and Extension of Cracks}

4.1. Numerical Simulation for Hydrofracturing. AE (acoustic emission) energy index is a reflection of hydraulic fracturing effect. The energy released in AE (acoustic emission) along the extension direction of slit-induced fracturing is investigated under different lateral pressure coefficients through 


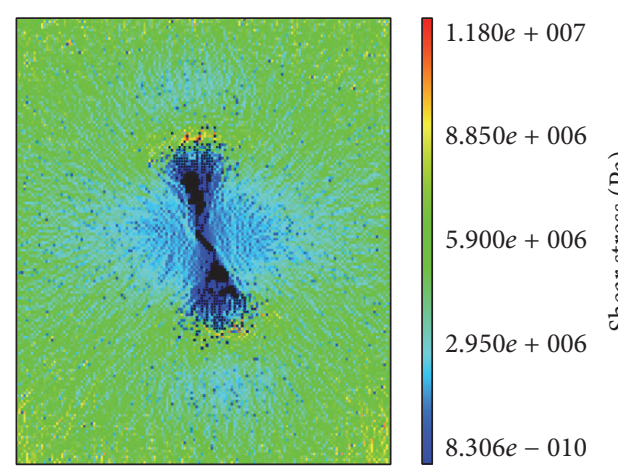

(a) $\sigma_{3}=11 \mathrm{MPa}$ and $\sigma_{1}=13 \mathrm{MPa}$

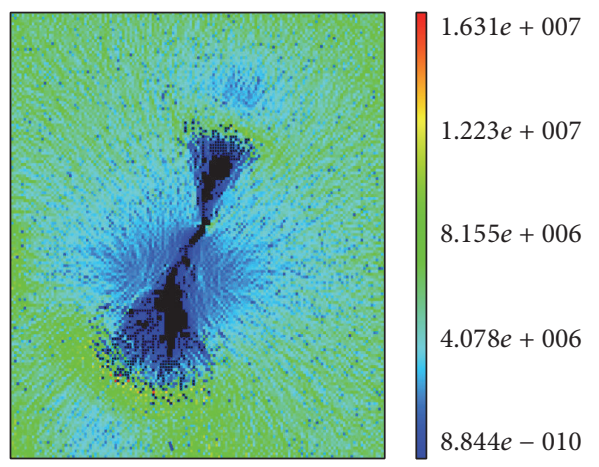

(c) $\sigma_{3}=12.5 \mathrm{MPa}$ and $\sigma_{1}=13 \mathrm{MPa}$
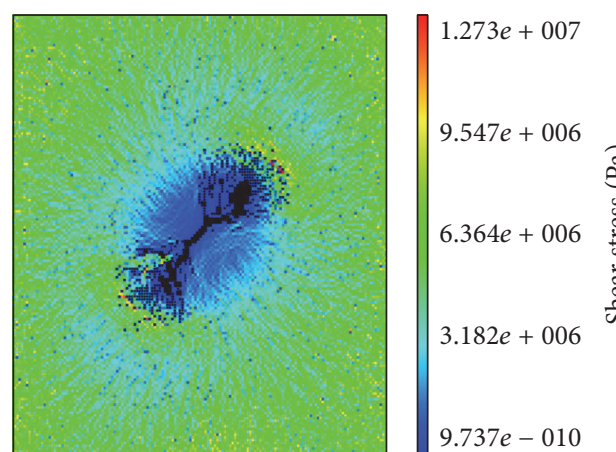

(e) $\sigma_{3}=13.5 \mathrm{MPa}$ and $\sigma_{1}=13 \mathrm{MPa}$
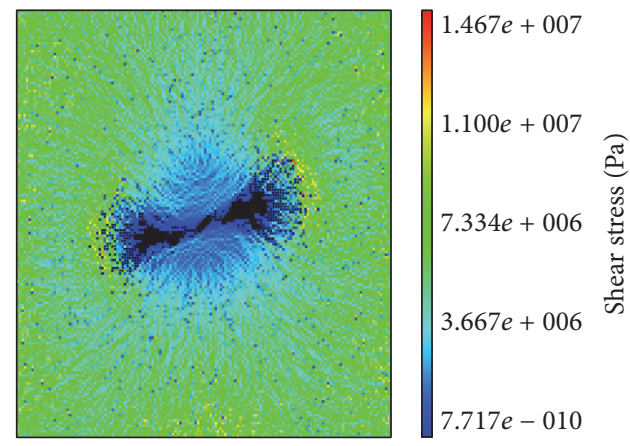

(g) $\sigma_{3}=15 \mathrm{MPa}$ and $\sigma_{1}=13 \mathrm{MPa}$

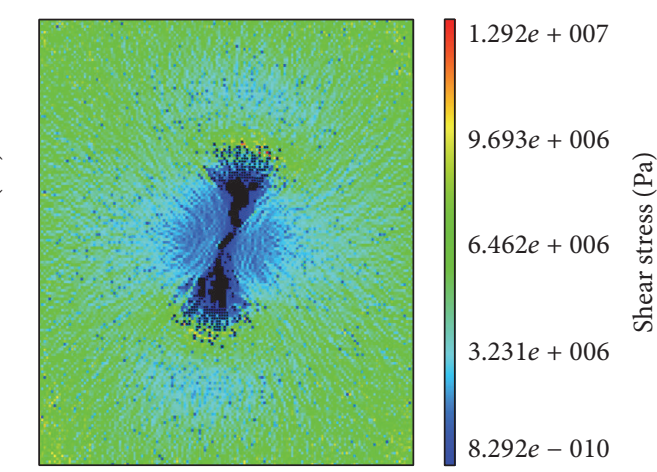

(b) $\sigma_{3}=12 \mathrm{MPa}$ and $\sigma_{1}=13 \mathrm{MPa}$

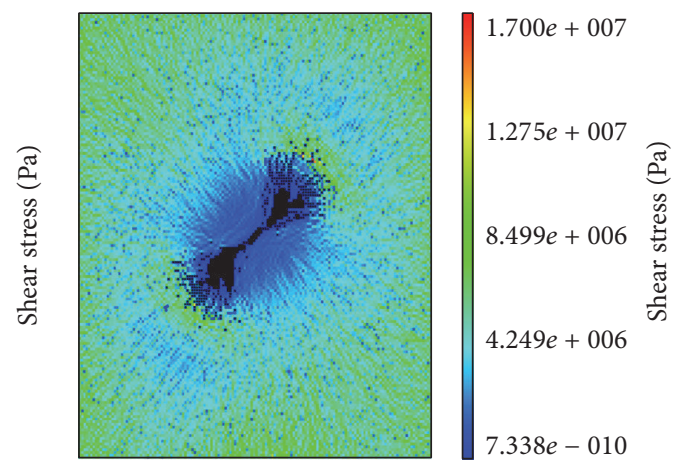

(d) $\sigma_{3}=13 \mathrm{MPa}$ and $\sigma_{1}=13 \mathrm{MPa}$

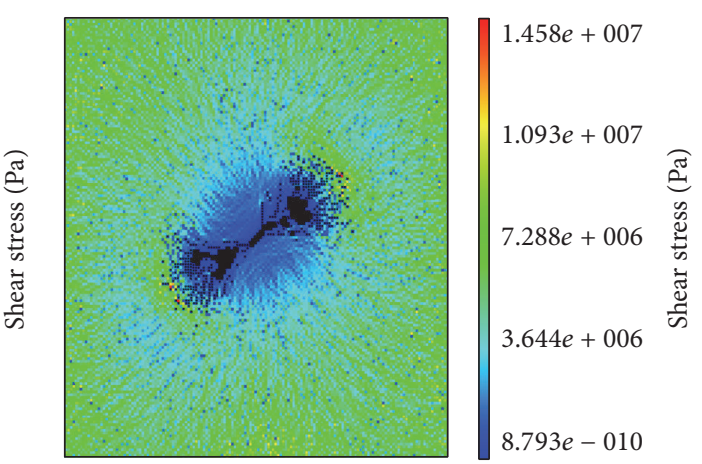

(f) $\sigma_{3}=14 \mathrm{MPa}$ and $\sigma_{1}=13 \mathrm{MPa}$

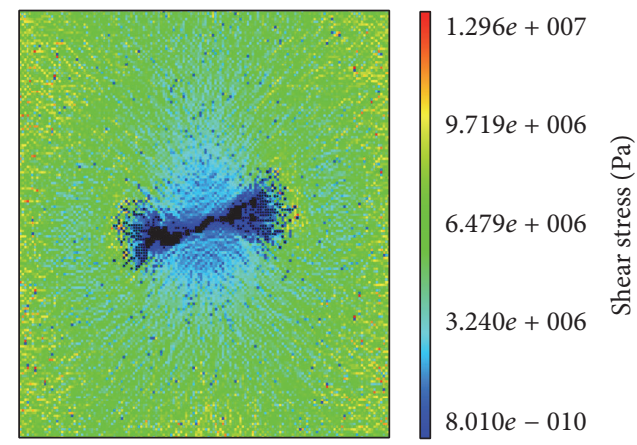

(h) $\sigma_{3}=16 \mathrm{MPa}$ and $\sigma_{1}=13 \mathrm{MPa}$

Figure 5: The final extensions of the cracks under different lateral pressure coefficients. 


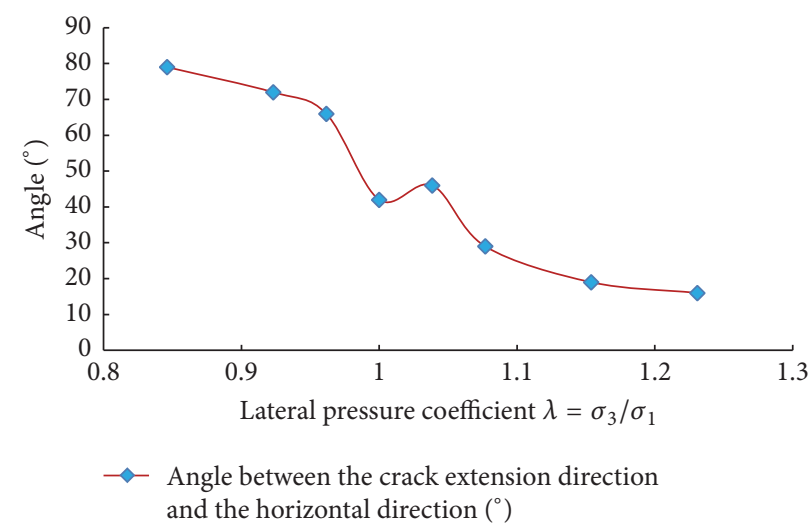

FIGURE 6: The angle between the crack extension direction and the horizontal direction under different lateral pressure coefficients.

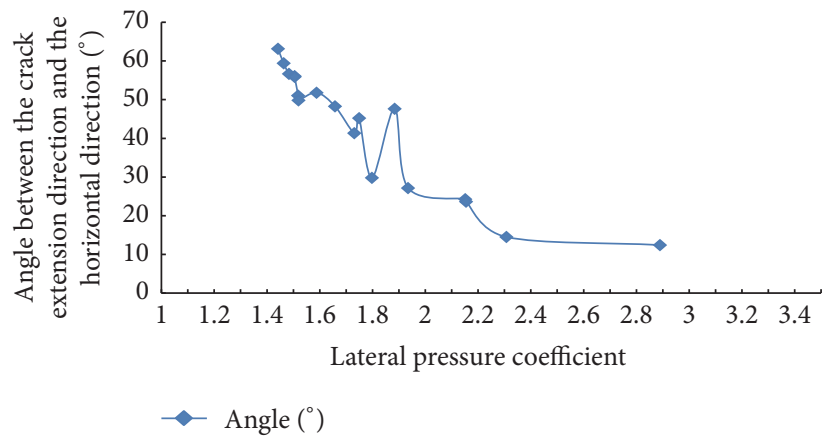

FIGURE 7: Relationship between the lateral pressure coefficient on site and the crack extension angle.

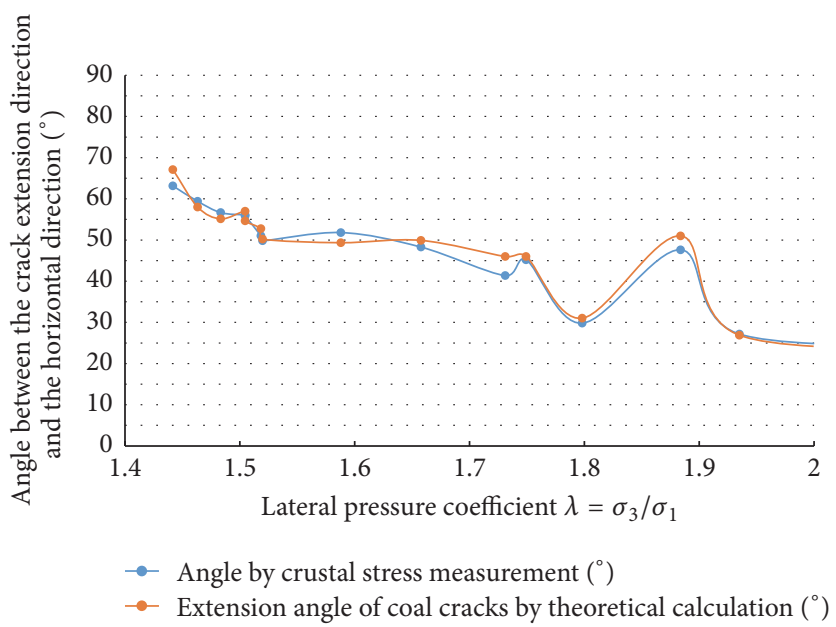

FIGURE 8: Comparison of the relationship between lateral pressure coefficient and the extension dip angle of slits in theoretical study and crustal stress measurement.

numerical simulation so as to select the radii for gas extraction in different coal mining faces. Numerical simulation model is shown in Figure 4. The red circles in Figure 9 represent the energy released in acoustic emission.

4.2. Hydrofracturing in Gas Drainage Project. In accordance with Figure 10, the energy released in acoustic emission under the condition of $\lambda=0.88$ is more than that released in the direction showing an angle of $45^{\circ}(\lambda=1)$ with the same operation step. When $\lambda$ equals 1.23 , the minimal energy is released in acoustic emission along the direction which shows an angle of $60^{\circ}$ between the extension direction of slitinduced fracturing and the horizontal direction.

Under the effect of stress-seepage, since the tensile strength of coal and rock masses is far lower than their compressive strength, coal and rocks are most likely to be 


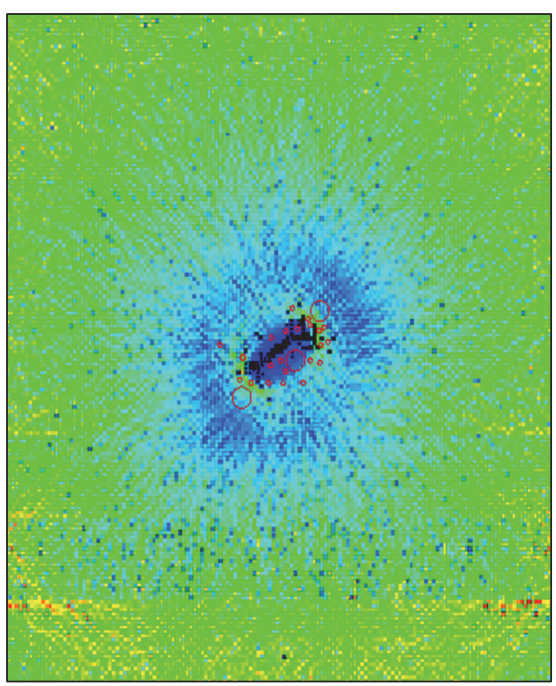

(a) Spatial AE in the direction showing an angle of $30^{\circ}$ between the extension direction of slit-induced fracturing and the horizontal direction $(\lambda=1.23)$

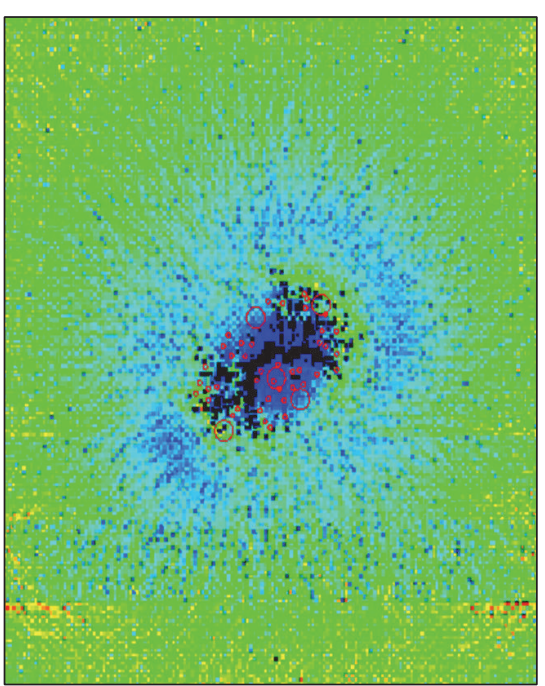

(b) Spatial AE in the direction showing an angle of $45^{\circ}$ between the extension direction of slitinduced fracturing and the horizontal direction $(\lambda=1)$

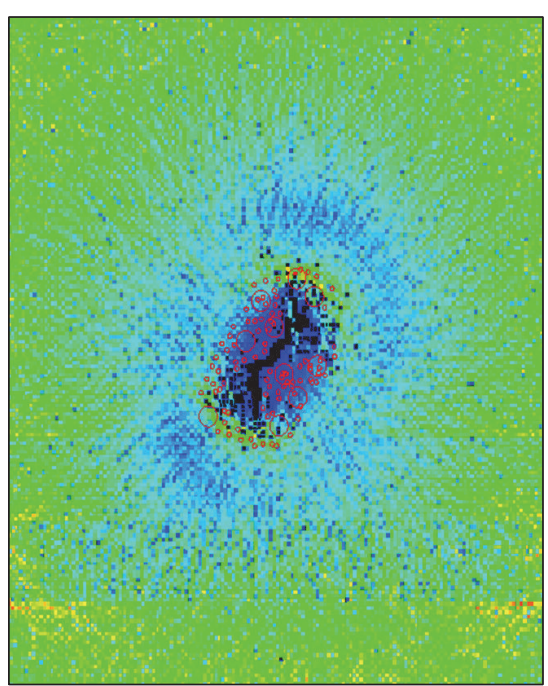

(c) Spatial acoustic emission in the direction showing an angle of $60^{\circ}$ between the extension direction of slit-induced fracturing and the horizontal direction $(\lambda=0.88)$

FIGURE 9: The AE images of hydrofracturing under three different lateral pressure coefficients.

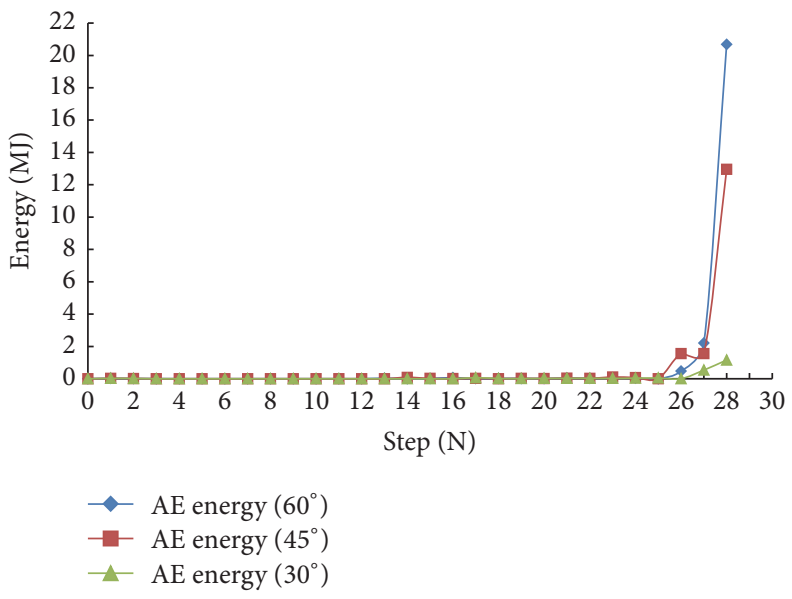

FIGURE 10: Relationship between AE energy and step number in hydrofracturing under three different lateral pressure coefficients.

destroyed when they are stretched. The prerequisite for crack failure is shown as follows:

$$
\begin{gathered}
\sigma_{N}>-\sigma_{t} \\
\sigma_{T}>-\sigma_{t},
\end{gathered}
$$

where $\sigma_{t}$ is the tensile strength of the coal and rock mass with unit of MPa and is a negative value.

Based on formulas (3), (4), and (11), the minimal pressure $P$ for hydrofracturing coal and rock masses is obtained. This indicates that lateral pressure coefficient is of great significance in selecting fracturing modes:

$$
\begin{aligned}
P & =\min \left\{\sigma_{1}\left(\sin ^{2} \beta+\lambda \cos ^{2} \beta\right)\right. \\
& \left.+\sigma_{t}, \sigma_{1}\left(\sin ^{2} \beta+\lambda \cos ^{2} \beta\right)+\sigma_{t}\right\} .
\end{aligned}
$$

Based on the above conclusion, after water was injected into regions $\mathrm{A}, \mathrm{B}$, and $\mathrm{C}$ at the same pressure of $P=20 \mathrm{MPa}$ for improving the permeability through fracturing, the gas in region $\mathrm{A}(\lambda=1.23)$ was finally extracted in a borehole distance of $1.5 \mathrm{~m}$, while the radii for gas extraction in regions $\mathrm{B}(\lambda=1)$ and $\mathrm{C}(\lambda=0.88)$ were set as $2 \mathrm{~m}$ and $3 \mathrm{~m}$, respectively, as illustrated in Figure 11. After $200 \mathrm{~d}$ of gas extraction, the extraction effect in a range of $50 \mathrm{~m}$ within the transportation roadway of the working face in number 8 coal seam was verified. The results show that the extraction efficiencies in the three regions were all about $75.1 \%$, showing a favorable extraction effect. In addition, cost was reduced as the construction quantity of boreholes was reduced under the condition of ensuring that all boreholes are applicable to gas extraction. 


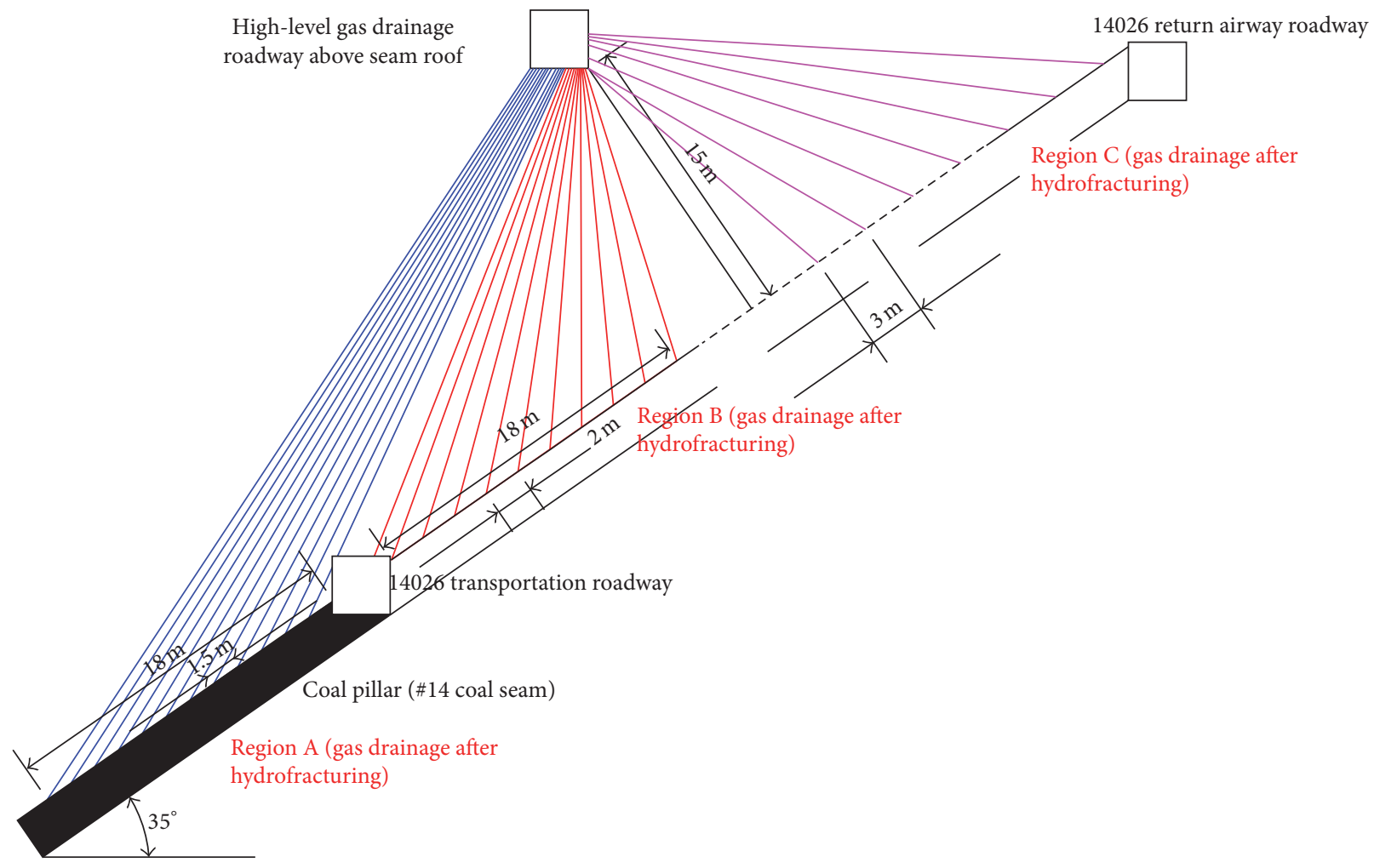

FIGURE 11: Gas extraction profile whose permeability is increased through fracturing.

\section{Conclusions}

(1) It was concluded from the RFPA2D simulation that the angle between the crack extension direction and the horizontal direction is inversely proportional to the lateral pressure coefficients.

(2) To realize the optimal design of coal mines, the conclusion presented in (1) was further validated while measuring the crustal stress and theoretic verification. That is, the applicability of the conclusion in general conditions was verified by investigating a special condition.

(3) Permeability-increasing radius is selected preferably through AE energy index by simulation of hydraulic fracturing for coal seams under different lateral pressure coefficient, and the gas drainage achieves good effect in engineering practice.

\section{Competing Interests}

The authors declare that they have no competing interests.

\section{Acknowledgments}

This work was supported by the project "Technology of Coalbed Methane Exploitation and Utilization for Great Tilt Angle Coal Seam Group in Xinjiang Coal Mine Area" funded by the Key National Science and Technology Subject (Grant no. 2016ZX05043005-005); the project "Management and Early Warning Technology of Gas Disaster Prevention and
Control in Coal Mine" funded by Shaanxi Province Science and Technology Plan Funds (Grant no. 2013K11-20); and China Postdoctoral Science Fund (Grant no. 2013M542366).

\section{References}

[1] X. Shan, S. Zhang, J. Zhang, and A. Li, "Analyzing the fracture extended law of hydraulic fracturing in coalbed gas wells," Natural Gas Industry, vol. 25, no. 1, pp. 17-132, 2005.

[2] B. Xia, K. Hu, Y. Lu, Y. Liu, and C. Song, "Mechanism of crack-oriented of hydraulic fracture and its technique in mine," Journal of Chongqing University, vol. 36, no. 9, pp. 8-13, 2013.

[3] L. Baiquan, Z. Qizhi, and S. Chunming, "Permeabilityincreasing mechanism of network slotting boreholes and application in crossing borehole gas drainage," Journal of China Coal Society, vol. 37, no. 9, pp. 1425-1430, 2012.

[4] L. Shugang, X. Lijie, and L. Chao, "Application of deep hole break-tip blasting technology in hard roof depressurization," Safety in Coal Mines, vol. 46, no. 2, pp. 128-131, 2015.

[5] G. Chenye, Q. Le, and L. Dong, "Effect of ground stress and initial fissure on crack initiation direction and pressure by hydraulic fracturing," Safety in Coal Mines, vol. 46, no. 2, pp. 161-165, 2015.

[6] W. Wei, C. Yuanping, and Y. Liang, "Floor fracture evolution and relief gas drainage timeliness in deeper underground shortdistance upper protective coal seam extraction," Journal of China Coal Society, vol. 41, no. 1, pp. 138-148, 2016.

[7] D. Zhang, W. Zhu, S. Li, and Y. Guo, "Influence of confining pressure and fissure water pressure on initial opening for ellipse facture," Chinese Journal of Rock Mechanics and Engineering, vol. 23, no. 2, pp. 4721-4725, 2004. 
[8] C. Yaoshun, Elasticity Mechanics, Tongji University Press, Shanghai, China, 2009.

[9] Z. Wang and S. Chen, Advanced Fracture Mechanics, Higher Education Press, Beijing, China, 2009.

[10] Y. Shouwen, Damage Mechanics, Tsinghua University Press, Beijing, China, 1997.

[11] L. Hongwen, Damage Mechanics, Higher Education Press, Beijing, China, 2003.

[12] G. Jianqing, Y. Ziquan, and T. Hui, "The effect of lateral pressure coefficient on deformation and stress distribution rules around roadway," Journal of Mining \& Safety Engineering, vol. 28, no. 4, pp. 566-575, 2011.

[13] H. Longxian, Y. Tianhong, and Z. Chao, "Influence of anisotropy on failure mode of tunnel under different later pressures," Journal of Northeastern University, vol. 33, no. 5, pp. 739-746, 2012.

[14] X.-B. Wang and Y.-S. Pan, "Numerical simulation of rockburst processes of a circular tunnel at different lateral pressure coefficients," Rock and Soil Mechanics, vol. 31, no. 6, pp. 19371945, 2010.

[15] L. Shugang, H. Yangsheng, and W. Hongsheng, "Numerical analysis on the influence of horizontal pressure coefficient on thin-lateral complex roof during the blasting driving roadway," Engineering Blasting, vol. 17, no. 4, pp. 5-10, 2011.

[16] W. Wang, Design and Analysis of Experiments, Higher Education Press, Beijing, China, 2004.

[17] L. Yunfang, "In-suit three-dimensional stress measurements by hydraulic fracturing technique," Chinese Journal of Rock Mechanics and Engineering, vol. 10, no. 3, pp. 246-256, 1991. 


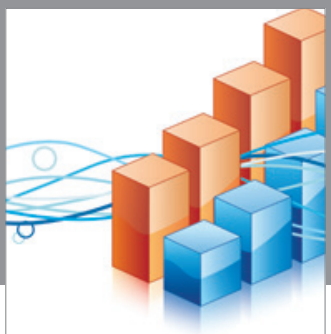

Advances in

Operations Research

vatem alat4

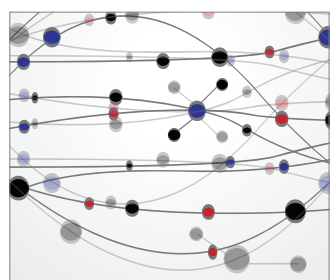

\section{The Scientific} World Journal
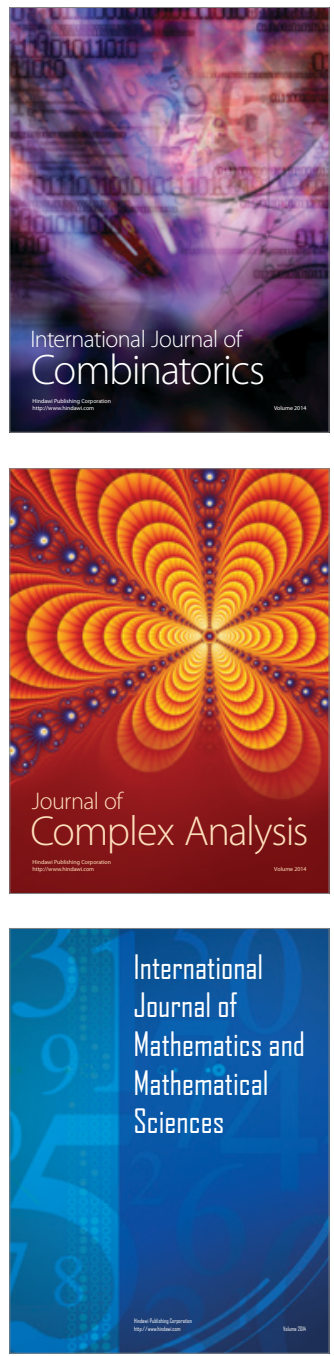
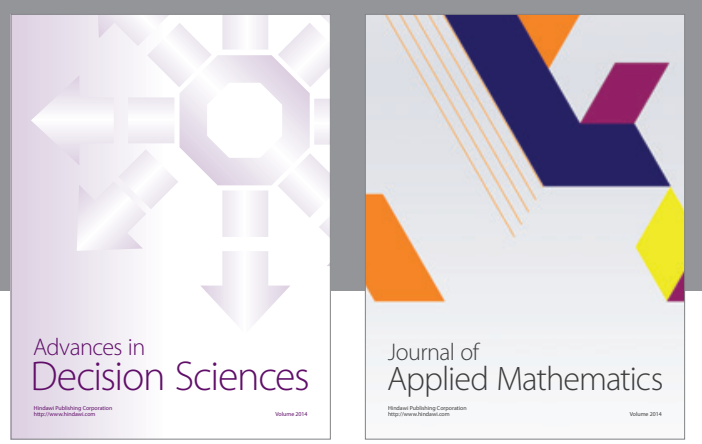

Algebra

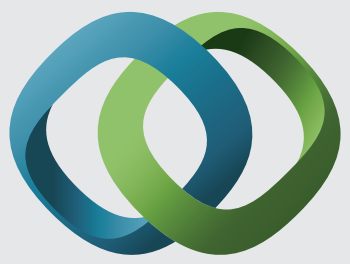

\section{Hindawi}

Submit your manuscripts at

http://www.hindawi.com
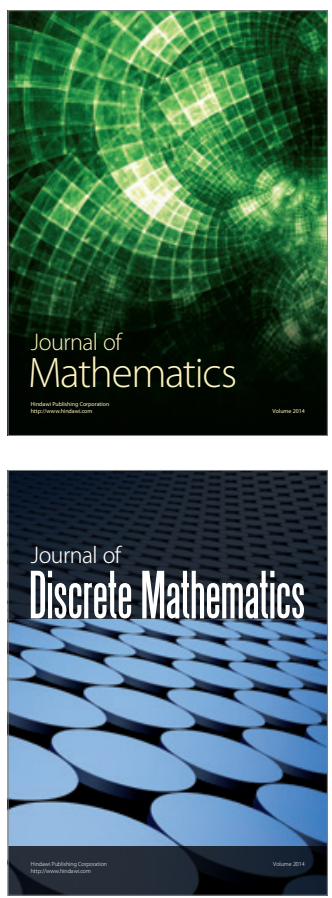

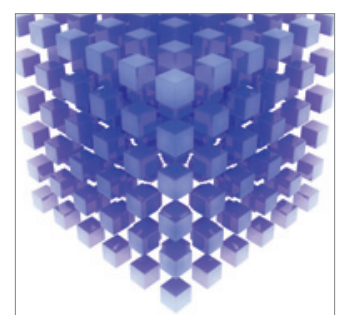

Mathematical Problems in Engineering
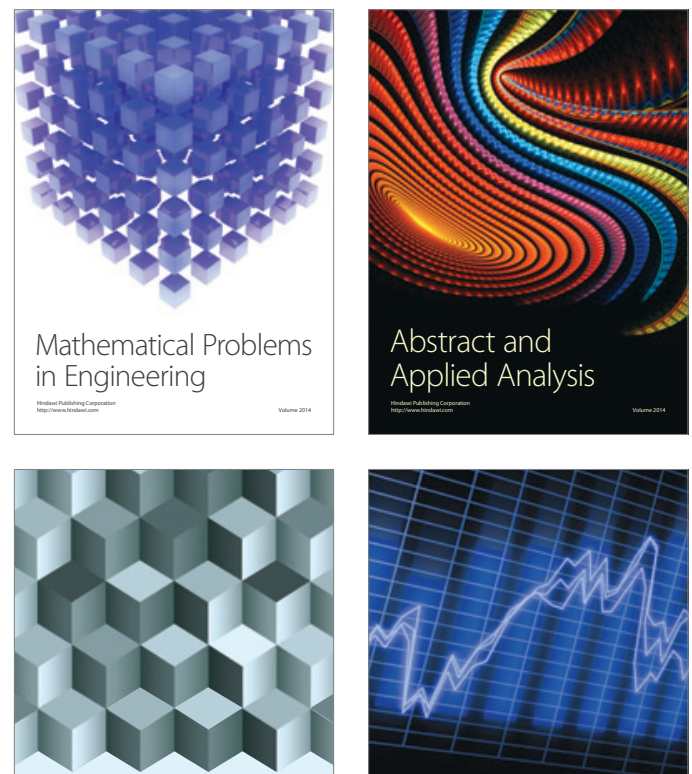

Journal of

Function Spaces

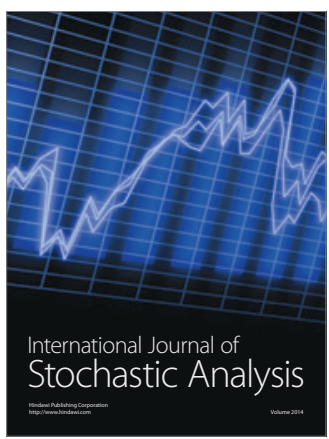

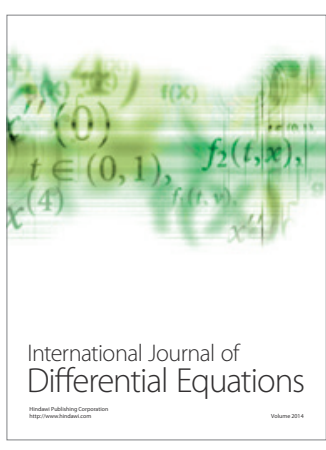
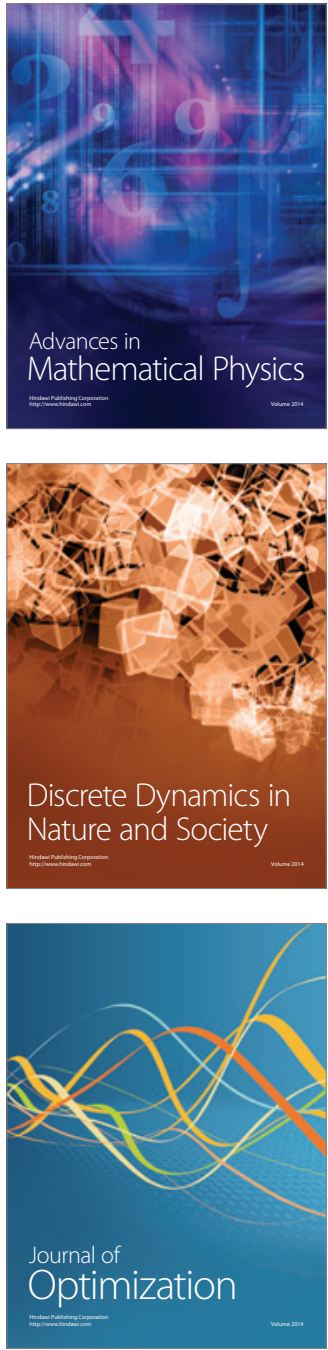